\title{
Vida inteligente no mundo das formigas
}

CARLOS ROBERTO F. BRANDÃO é mestre e doutor pelo Departamento de Zoologia do IBUSP e curador da coleção Hymenoptera (abelhas, vespas e formigas) do Museu de Zoologia da

USP.

The Ants, Bert Hölldobler e Edward O. Wilson, Belnak Press, 732 pp.

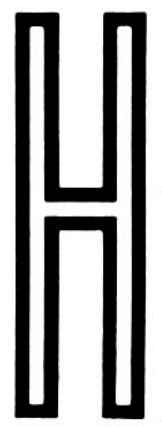

á dois anos o pequeno grupo de biólogos que estuda as formigas recebeu a notícia de que os professores de Harvard, Bert Hölldobler e Edward O. Wilson, preparavam um livro-revisão. Alguns conheceram previamente partes da publicação, mas o impacto do volume pronto até agora repercute. O livro (The Ants, US\$ 64 nos EUA, mas que chega aqui a inexplicáveis US\$120), publicado em meados de 1990 , tem grande formato $(3,2 \mathrm{~kg}$, capa dura), 732 páginas em coluna dupla, 23 magníficas pranchas coloridas e centenas de ilustrações, tabelas, gráficos, etc., além de 10 páginas de glossário, cerca de 3.200 referências e 20 páginas de índice de autores e assuntos. As tabelas, que reúnem sinteticamente informações de inúmeros trabalhos dispersos na literatura, já foram apontadas como a grande força do livro. Outros indicam as ilustrações, que permitem visualizar com precisão o fenômeno que está sendo descrito; outros, ainda, a lista de referências.

Desde que o livro chegou ao mercado não faltam nas reuniões científicas de especialidade, no mundo todo, comentários sobre quem foi citado e quantas vezes, o que dá uma idéia da influência dos autores nesta comunidade.

Wilson é hoje um dos cientistas mais famosos e respeitados dos EUA. Alguns de seus livros anteriores, em especial o capítulo sobre a espécie humana no Sociobiology: The New Syntesis, de 1975 (mesma editora), geraram polêmicas e praticamente um cisma na Biologia de Harvard. Um grupo autocaracterizado como de ultra-esquerda o atacou de forma violenta, colaborando em muito para a divulgação das idéias propostas no livro até na grande imprensa. Este debate está hoje ultrapassado e a contribuição da sociobiologia já foi depurada por um meio extremamente crítico, apesar de não tão "ideologicizado". O livro atual marca a volta de Wilson à mirmecologia (myrmex = formiga, em grego), tanto que no momento ele prepara uma revisão mundial do gênero Pheidole (mais de 1.000 nomes ao nível de espécie na literatura), que os taxônomos e curadores de coleções de formigas esperam com ânsia ainda maior.

The Ants recebeu críticas francamente favoráveis da grande maioria dos especialistas em revistas científicas. Contribuindo para sua maior divulgação os autores receberam ainda o Prêmio Pulitzer na categoria não-ficção, sendo Wilson o primeiro cientista a recebê-lo duas vezes (a primeira por On Human Nature, em 1978 - uma aplicação mais aprofundada dos preceitos da sociobiologia ao estudo do comportamento social humano).

Toda esta expectativa e publicidade refletem o nível do trabalho que vem sendo desenvolvido nos últimos anos por esses dois cientistas no laboratório do 4ㅇ andar do prédio anexo ao Museum of Comparative Zoology de Harvard.

Hölldobler, atualmente na Universidade de Wurzburg, mas mantendo sua ligação com Harvard, é sem dúvida o pesquisador que mais tem contribuído para uma melhor compreensão dos mecanismos envolvidos na comunicação - um fator decisivo na estrutura das comunidades de formigas. Seus trabalhos mesclam elegantemente morfologia, neurofisiologia, ecologia e genética de populações. Não havia, entretanto, escrito trabalho de revisão assim tão ambicioso. 
Wilson, já em um dos seus primeiros trabalhos, publicado no fím da década de 40, também em português nos "Anais do Instituto Oswaldo Cruz" sobre as lava-pés (gênero Solesopsis, grupo de espécies saevissima - formiga de triste fama na matriz "imported fire ant", imported do Brasil e claro), introduz a marca de seu estilo. Reúne uma quantidade tão maciça de provas que a interpretação fica quase irrefutável. Seu livro que mais se assemelha ao texto em questão é The Insect Societies, de 1971 (também da mesma editora), ainda a fonte básica de informações sobre comportamento social dos insetos. Deve-se ainda destacar o livro de 1968, co-autoria de Robert H. MacArthur (The Theory of Island Biogeography, Princeton Univ. Press), que teve enorme influência na interpretação de padrōes evolutivos, apesar de hoje parecer um pouco datado, Caste and Ecology of Social Insects, co-autoria de G. F. Oster, de 1978 (Princeton Univ. Press) e o ensaio Biophylia (Belknap Press of Harvard Univ. Press), sobre a sempre premente necessidade do homem de estudar a natureza, considerado por alguns seu texto mais instigante. Os seus mais de trezentos trabalhos científicos, publicados ao longo de quarenta anos, são escritos de forma muito clara e tratam de todos os temas fundamentais no estudo de formigas.

Logo na introdução do The Ants os autores deixam claro que,
"The Ants" (As Formigas)

recebeu críticas

francamente favoráveis

da grande maioria

de especialistas em

revistas científicas.
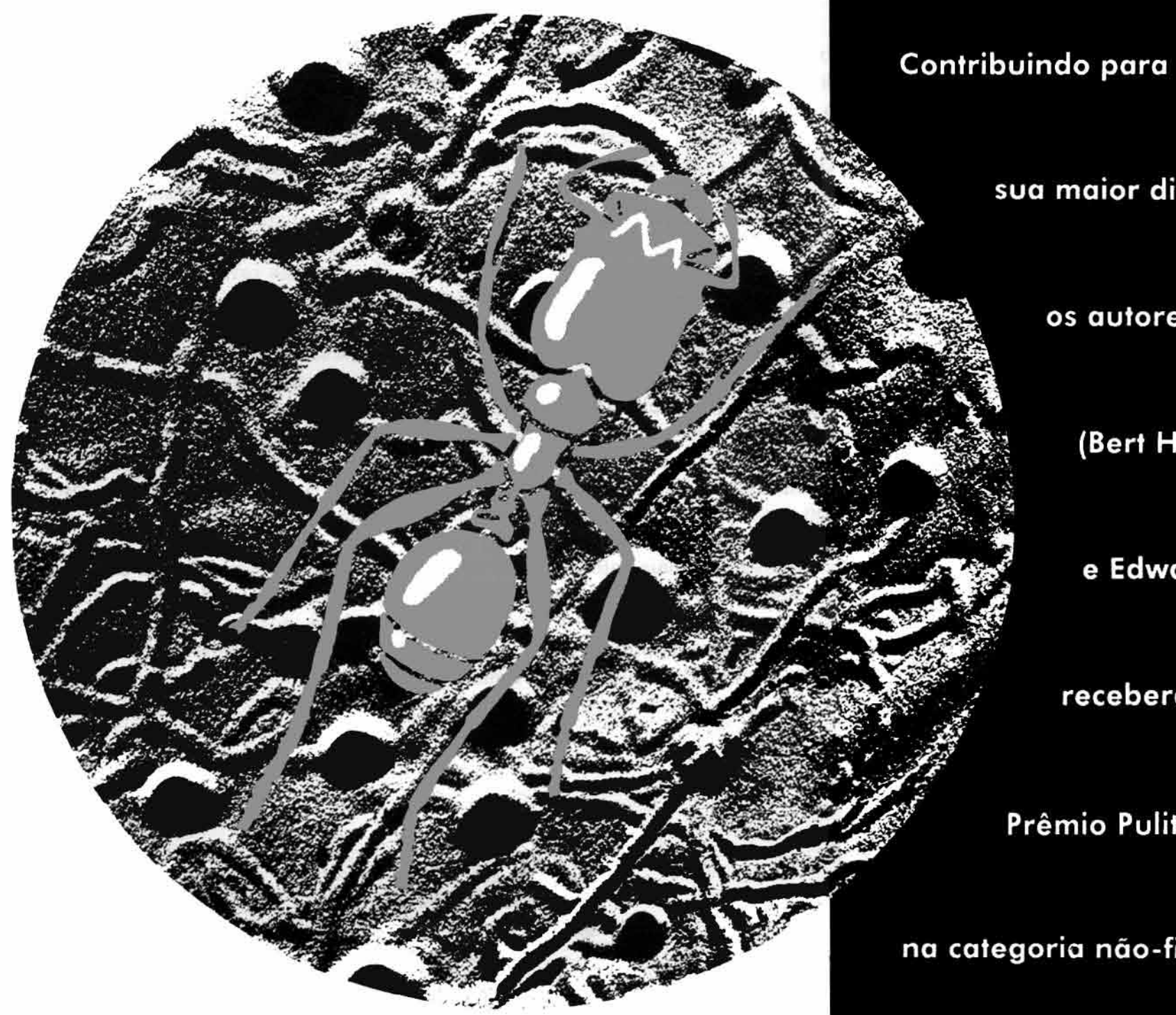

sua maior divulgação

os autores

(Bert Höldobler

e Edward Wilson)

Prêmio Pulitzer

receberam o 
na realidade, as formigas ê que dominam a Terra há quase cem milhões de anos. Por exemplo, em riqueza e diversidade de espécies, além de abundância e biomassa, ultrapassam todos os vertebrados terrestres na Amazônia. Lá mesmo, entretanto, perdem em biomassa para os peixes e em outras regiões do globo para nós humanos. Dessa forma justificam seu estudo e a propriedade de se reunir as informações que se tem sobre elas em um volume.

O número e diversidade dos temas tratados no livro impedem, no entanto, um reestudo de todos os assuntos cobertos. Isto já fica explícito no segundo capítulo (taxonomia, morfologia e termos aplicados às partes duras do exoesqueleto), que apresenta as interpretações de diversos especialistas, mas ignora suas idiossincrasias, suas dificuldades, incongruências e omissões. O capítulo inclui uma proposta original de classificação dos gêneros do mundo, indicando sua distribuição por região zoogeográfica, seguida de uma chave para sua classificação e ilustrações da maioria deles, retiradas de trabalhos de especialistas.

William L. Brown Jr., de Cornell, lembrou em sua revisão do livro no Scientific American, que pode representar um desserviço a divulgação destas informações ao nãoespecialista, já que muitos destes gêneros têm limites pouco precisos e nosso conhecimento sobre eles é, no mínimo, fragmentário e desigual. Essa crítica perderia força se o leitor sequioso de atribuir nomes fosse ao menos advertido dessas limitações. Não cabe dúvida, no entanto, que o glossário de termos representa um avanço e a reunião das figuras uma facilidade.

A primeira metade do livro trata de temas gerais no estudo de formigas, começando com a fundação e ciclo de vida da colônia, seus estágios de desenvolvimento, época e tipo de vôo nupcial, cuidado à prole e demografia. Comentam ainda as condições que facilitam ou determinam as migrações para novos ninhos e as estratégias alternativas para os ciclos de vida.

Em seguida é tratado o tema do altruísmo e origem de uma casta estéril em formigas, de hábito e conformação muito diferentes da casta reprodutiva. Altruísmo no sentido biológico, onde certos indivíduos (no caso operárias) abrem mão de seu potencial reprodutivo (isto é, se tornam estéreis ao longo da evolução), e empregam sua energia na reprodução de outros da mesma espécie (suas mães, as rainhas). Esta questão é fundamental, já tendo sida tratada atê por Darwin na Origem das Espécies. Como pode um grupo de indivíduos estéreis acumular características próprias? A discussão envolve, como também já dito por Darwin, níveis de atuação dos mecanismos chamados genericamente de seleção natural, o que significa dizer uma boa parte das teorias modernas da biologia evolutiva. Hölldobler e Wilson apresentam e discutem as principais hipóteses, seus méritos e críticas, de forma até onde possível isenta. Conseguem simplificar temas complexos sem perda da precisão nos conceitos.

Preparam dessa forma o leitor para os capítulos seguintes, onde discutem os mecanismos de causação envolvidos na comunicação e como eles atuam na discriminação individual, colonial e entre espécies (habilidade de reconhecimento e sua ontogenia, fonte de estímulos químicos, agressão e dominação rainha-operária e operária-rainha). Investigam as conseqüências evolutivas da ginia (número de rainhas ativas em uma colônia) e das ordens de dominância, comentando os casos estudados. Apesar dos trabalhos pioneiros de Wilson nessa área, Hölldobler é hoje a autoridade maior nesse assunto, o que pode se sentir nessas páginas.

Talvez um dos assuntos mais interessantes ali tratados seja a modulação da comunicação. Os sinais não provocam nas formigas respostas apenas do tipo tudo-ou-nada. $\mathrm{Pa}-$ recem, sim, ajustar o comportamento dos membros da colônia, adequando-o finamente às mudanças nas condições ambientais, ainda que empregando quantidade relativamente baixa de bits. Isto é verdade tanto para a emissão quanto para a recepção de informa-
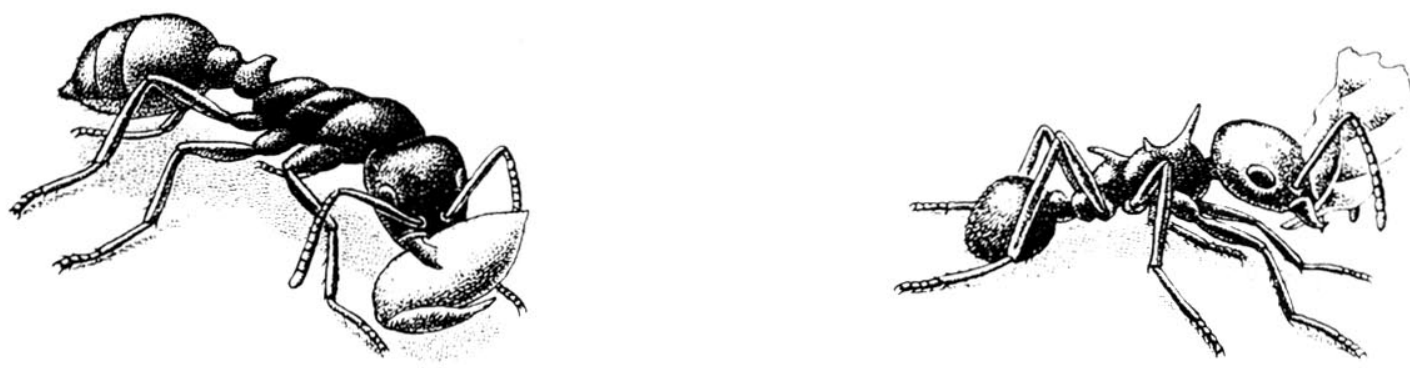
ções, que no caso de formigas utilizam principalmente via química, mas envolvem em maior ou menor grau sinais táteis e visuais, dependendo da espécie.

Os níveis elaborados de comunicação permitem a co-existência na colônia de indivíduos especializados, as subcastas de operárias, com morfologias distintas e adequadas a certas funções, possibilitando o aperfeiçoamento de um eficiente sistema de divisão de trabalho. A origem e evolução das castas físicas, baseadas principalmente no crescimento diferencial das partes do corpo, isto $\varepsilon$, na alometria, geram uma demografia de natureza adaptativa, sujeita a fatores da ecologia.

Nos capítulos onde comentam as teorias sobre o aparecimento e evolução das castas e sua determinação é nítida a orientação de Wilson. $O$ texto conduz muito bem a discussão sobre o quanto de flexibilização e aprendizado este sistema, aparentemente tão rígido, suporta e como ele opera, do nível individual até o da colônia. Mais ainda, como isto tudo varia entre colônias.

Pena que não seja ainda possível aplicar este conhecimento para uma melhor discriminação entre espécies. Há um sentimento crescente entre os taxônomos de que é muito maior do que se supunha o número de espécies crípticas, isto $E$, aquelas que se discriminam bem e não se cruzam em condições naturais, apesar de nossos olhos, mesmo com auxflio das mais poderosas e modernas ferramentas, não serem capazes de as diferenciar. Certamente a comunicação intra-específica exerce papel fundamental na discriminação entre espécies de formigas.

Os capítulos sobre ecologia exploram as informações sobre forrageamento, estratégias territoriais e modos de competição. São citados os casos observados na natureza de competição intra e interespecífica, pouco documentados em outros grupos animais. A partir daí estamos preparados para compreender a organização das comunidades locais e toda sua plasticidade. Discutem então os casos conhecidos de expansão e retração na distribuição de táxons de formigas, através da análise de distribuições atuais e do registro fóssil.

Finalizando esta série de capítulos e numa seqüência natural na forma de organização do livro, tratam das relações entre espécies de formigas, delas com outros insetos, com outros artrópodos e com plantas. Infelizmente não discutem a, muitas vezes, tumultuada relação das formigas com o homem e todas suas implicações econômicas e higiênicas, deixando para outros a tarefa de propor formas de avaliação do impacto dessa relação e modos de combate adequados.

Os capítulos 15 a 19 representam estudos-de-caso muito bem ilustrados sobre as predadoras especializadas, as formigas-de-correição do Velho e do Novo Mundo, as cortadeiras - as exclusivamente neotropicais saúvas, quem-quens e gêneros próximos - e, por fim, as formigas coletoras de sementes e as tecelãs arborícolas (segmento relativamente pouco importante ou não tão bem estudado da fauna neotropical).

Encerra o livro um capítulo dedicado às metodologias de coleta, criação e observação de formigas. Muitas dessas técnicas foram desenvolvidas pelos próprios autores, mas, com certeza, muitos gostariam de conhecer melhor os métodos que Hölldobler emprega nas suas magníficas preparações histológicas de glândulas.

As poucas críticas ao livro parecem refletir mais decepções daqueles que gostariam que o texto tratasse melhor dúvidas suas, do que representar restrições reais quanto ao conteúdo. Alguns dizem que os autores são tendenciosos, privilegiando citar trabalhos seus ou daqueles que passaram por seu laboratório. Chamam o texto de "Harvard biased", o que não se pode dizer que comprometa por si só o resultado final.

Mesmo a casa editora não devolvendo o dinheiro eventualmente investido na compra do livro, poucos deverão se arrepender de possuir um volume com tal concentração de informações, apresentadas com tanto apelo, de forma clara, concisa e fartamente ilustrada. Mesmo em tempo de vacas magras.
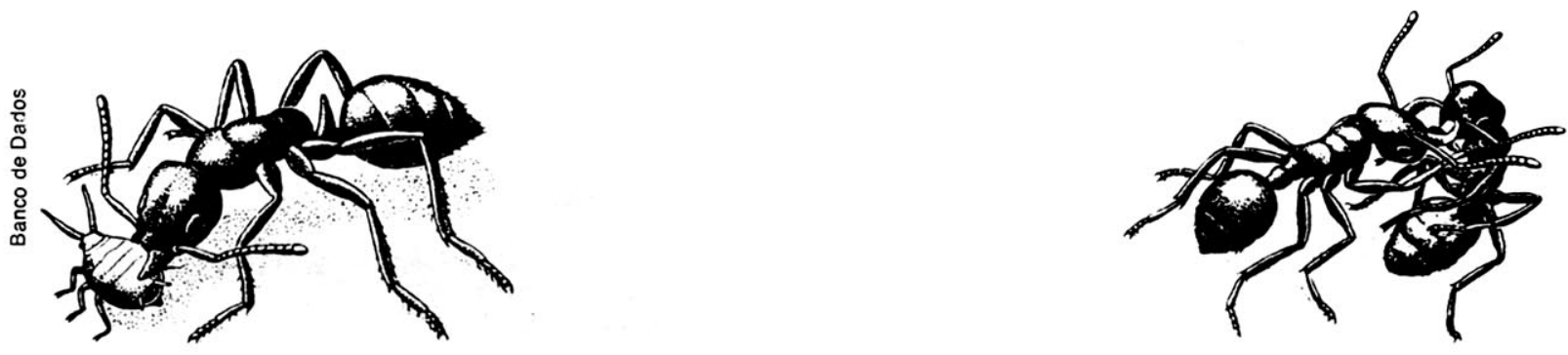